\title{
The role of thermal analysis in the development of high-iron-content kaolinite-based photocatalysts
}

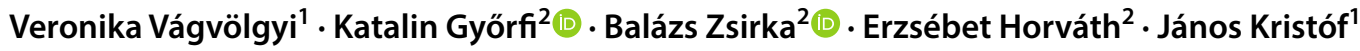

Received: 3 September 2019 / Accepted: 13 January 2020 / Published online: 3 February 2020

(c) The Author(s) 2020

\begin{abstract}
Dynamic and controlled-rate thermogravimetric analyses have been carried out on acid-treated (11 and $5.8 \mathrm{M} \mathrm{HCl})$, highiron-content kaolinites as potential photocatalysts. The mineral contaminants were determined by XRD, while the defect sites of reduced coordination number obtained by surface treatments were identified with ${ }^{27} \mathrm{Al}$ MAS NMR spectroscopy. Upon heating, water is evolved from the surface-treated samples in three main stages: (1) removal of adsorbed water up to $\sim 200{ }^{\circ} \mathrm{C}$, (2) goethite dehydroxylation between 200 and $350{ }^{\circ} \mathrm{C}$ and (3) dehydroxylation of the clay in the $300-700{ }^{\circ} \mathrm{C}$ temperature range. Identification of water released from the above mass loss steps is difficult due to the significant overlap of steps 2 and 3 , as well as to the presence of coordinated water at broken edges and defect sites $\left(-\mathrm{OH}_{2}^{+}\right.$groups). As a result, the thermal behavior of surface-treated kaolinites should be taken into account both in the preparation of hybrids/composites and in the acid-base characterization of the catalytic surface.
\end{abstract}

Keywords Kaolinites $\cdot$ Photocatalysis $\cdot$ Surface modification $\cdot$ CRTA

\section{Introduction}

Kaolinite is a 1:1 type layered silicate with the general formula $\mathrm{Al}_{2} \mathrm{Si}_{2} \mathrm{O}_{5}(\mathrm{OH})_{4}$ consisting of a two-dimensional arrangement of Si-centered tetrahedra and a two-dimensional arrangement of Al-centered octahedra. There are three types of $\mathrm{OH}$ groups located along octahedral edges: The socalled inner $\mathrm{OH}$ groups (iOHs) are in the plane common to both the tetrahedral and octahedral sheets and are not accessible by reagent molecules. The so-called inner-surface $\mathrm{OH}$ groups (is $\mathrm{OH}$ ) form strong hydrogen bonds with the oxygen sheet of the next double layer. The $\mathrm{OH}$ groups located on the outermost surface of the particles and along broken edges are called as outer-surface $\mathrm{OH}$ groups (osOHs). The double layers held together via $\mathrm{H}$ bonds show a parallel orientation along the 'c' axis (book-type arrangement). The basal distance is around $7.1 \AA$. With suitable reagents (e.g., with short-chain fatty acids), the $\mathrm{H}$ bonds holding together the

Erzsébet Horváth

erzsebet.horvath@gmail.com

1 Department of Analytical Chemistry, University of Pannonia, Egyetem u. 10, Veszprém 8200, Hungary

2 Institute of Environmental Engineering, University of Pannonia, Egyetem u. 10, Veszprém 8200, Hungary double layers can be broken up, leading to the formation of intercalation complexes. (The double layers are separated by individual reagent monolayers.) With cascade intercalation, the clay can be separated to individual double layers. (This process is called as exfoliation.) The $\mathrm{OH}$ groups along octahedral edges result in polar TO layers of hydrophilic nature [1].

In the last decade, the results on the composites and hybrids of the 1:1 type clay minerals along with their novel surface modification procedures opened new horizons of application such as the development of self-cleaning surfaces [1] or photocatalytic materials [2-8].

The iron contamination of clays is primarily due to the accompanying oxides, oxyhydroxides and carbonates. The contaminating oxides and oxyhydroxides are magnetite $\left(\mathrm{Fe}_{3} \mathrm{O}_{4}\right)$, hematite $\left(\mathrm{Fe}_{2} \mathrm{O}_{3}\right)$, lepidocrocite $(\gamma-\mathrm{FeOOH})$ and goethite $(\alpha-\mathrm{FeOOH})$, while the carbonates are mainly in the form of siderite $\left(\mathrm{FeCO}_{3}\right)$. These contaminants can influence the porosity, while the $\mathrm{Fe}_{2} \mathrm{O}_{3}$ itself is a photocatalytic compound. Incorporation of iron in the crystal structure can also occur as a "structural" contaminant. In natural kaolinites, $\mathrm{Fe}^{3+}$ can substitute $\mathrm{Al}^{3+}$ in the octahedral sheets, amounting to even $2-6 \mathrm{~m} / \mathrm{m} \%$. Little information is available on the possible effects of iron substitution as yet. Replacement of $\mathrm{Al}^{3+}$ ions (ionic radius $0.051 \mathrm{~nm}$ ) by $\mathrm{Fe}^{3+}$ ions (ionic 
radius $0.064 \mathrm{~nm}$ ), or less likely by $\mathrm{Fe}^{2+}$ ions (ionic radius $0.074 \mathrm{~nm}$ ), in the octahedral layer can occur without a significant deterioration of the crystal structure. Incorporation of iron in the crystal lattice can most likely happen at three points: at structural discontinuities (broken particles), at stacking defects or at the outermost surfaces [9-13].

Due to its similar size, $\mathrm{Fe}^{3+}$ can replace the central $\mathrm{Al}$ atoms, resulting in catalytically important active acidic sites. In general, every surface treatment (e.g., thermal treatment or mechanical activation) results in some defect sites in the structure. Also, deposition of transition metal oxides onto the surface by heat treatment can cause defect sites due to the partial dehydration/dehydroxylation, leading to the reduction of the $\mathrm{Al}$ coordination number [14]. Therefore, the use of thermal analysis is of high importance from materials structure elucidation and technological points of view $[15,16]$.

Although thermal events are generally identified by peak temperature and enthalpy change data, it is important to emphasize that crystal modifications, the particle size, the overlapping processes, as well as the surface reactivity of the contaminants, can significantly influence the thermal behavior. In spite of these difficulties, thermal analysis plays a significant role in the development of clay-based catalysts, catalyst composites and hybrids. The application of kaolins with iron-bearing contaminants in environmental technologies can be justified with their low price and environmentally friendly nature. On the other hand, their porosity is undesirable from catalytic points of view, which can be improved via surface modification (e.g., by acidic treatment). After acidification active centers are formed, significantly influencing the surface properties [17].

The surface properties (e.g., acid-base characteristics) of both kaolinites and $\mathrm{OH}$-containing aluminosilicates are strongly influenced by the proton-acceptor interactions. Therefore, the thermoanalytical investigations are of utmost importance in the surface qualification of oxide catalysts of high surface $\mathrm{OH}$ content. In our analytical chemical approach, we demonstrate-through the example of an iron-containing kaolin as a potential photocatalystthat with the use of thermoanalytical methods the methodological errors of structure and surface characterization techniques (e.g., XRD, TPD) can be eliminated.

\section{Materials and methods}

\section{Surface treatment of high-iron-content kaolin}

The kaolin sample (from Felsôpetény, Hungary) contains $5.05 \pm 0.02 \mathrm{~m} / \mathrm{m} \% 11 \mathrm{M} \mathrm{HCl}$-soluble and $0.50 \pm 0.02 \mathrm{~m} / \mathrm{m} \%$ structural iron (in $\mathrm{Fe}_{2} \mathrm{O}_{3}$ equivalents). Defect sites were made in the kaolinite structure by acid treatment and exfoliation (with replacement intercalation). The samples with their designations as well as the ways of their treatment are summarized in Table 1. Since the preparation of the nanokaolinite via replacement intercalation was published earlier [18], Table 1 contains the main preparation steps only.
Table 1 Designation of samples and the ways of their surface treatment

\begin{tabular}{|c|c|c|c|c|c|c|c|c|}
\hline \multirow{4}{*}{$\begin{array}{l}\text { Designation } \\
\mathrm{K}\end{array}$} & \multicolumn{8}{|c|}{ Way of surface treatment } \\
\hline & \multicolumn{8}{|c|}{ Raw kaolin, oxidic composition in $\mathrm{m} / \mathrm{m} \%$} \\
\hline & $\mathrm{SiO}_{2}$ & $\mathrm{Al}_{2} \mathrm{O}_{3}$ & $\mathrm{CaO}$ & $\mathrm{MgO}$ & $\mathrm{K}_{2} \mathrm{O}$ & $\mathrm{Na}_{2} \mathrm{O}$ & $\mathrm{Fe}_{2} \mathrm{O}_{3} *$ & $\mathrm{H}_{2} \mathrm{O}$ \\
\hline & 56 & 22 & 0.3 & 0.6 & 1.1 & 0.1 & 5.55 & $10-13$ \\
\hline Knano & \multicolumn{8}{|c|}{$\begin{array}{l}\text { Nano-kaolinite obtained by replacement intercalation and exfoliation [18]: } \\
\text { 1) Precursor }(\mathrm{P}): \mathrm{K}+\text { potassium acetate }(\mathrm{KAc}) \text { complex }(\mathrm{K}-\mathrm{KAc}) \\
\mathrm{K} / \mathrm{Ac}=70: 30 \mathrm{~m} / \mathrm{m} \% \text { mixture exposed to air for } 5 \text { days and then dried at } 110^{\circ} \mathrm{C} \text {; } \\
\text { 2) Intercalation with ethylene glycol }(\mathrm{EG}) \text { complex }(\mathrm{K}-\mathrm{EG}) \\
\mathrm{K}-\mathrm{KAc}+\mathrm{EG} \text {, stirring for } 3 \mathrm{~h} \text { at } 150{ }^{\circ} \mathrm{C} \text {, centrifugation and drying } \\
\text { 3) Intercalation with } n \text {-hexylamine }(\mathrm{HA}) \text { complex }(\mathrm{K}-\mathrm{HA}) \\
1 \mathrm{~g} \mathrm{~K}-\mathrm{EG}+5 \mathrm{~mL} \mathrm{HA} \text {, stirring at room temperature for } 60 \mathrm{~h} \text { in Ar atmosphere, } \\
\text { centrifugation, drying at room temperature; this process repeated three times } \\
\text { 4) Exfoliation: washing with toluene (T) } \\
1 \mathrm{~g} \mathrm{~K}-\mathrm{HA}+5 \mathrm{~mL} T \text {, stirring at room temperature for } 5 \mathrm{~h} \text {, centrifugation and dry- } \\
\text { ing at room temperature } \\
\text { 5) surface cleaning: washing with isopropanol, acetone and Milli-Q water }\end{array}$} \\
\hline Knano-11 M HCl & \multicolumn{8}{|c|}{$\begin{array}{l}\text { Nano-kaolinite (obtained by replacement intercalation and exfoliation) mixed in } \\
11 \mathrm{M} \mathrm{HCl} \text { for } 6 \mathrm{~h} \text { at room temperature }\end{array}$} \\
\hline $\mathrm{K}-11 \mathrm{M} \mathrm{HCl}$ & \multicolumn{8}{|c|}{ Kaolin, mixed in $11 \mathrm{M} \mathrm{HCl}$ for $6 \mathrm{~h}$ at room temperature } \\
\hline $\mathrm{K}-5.8 \mathrm{M} \mathrm{HCl}$ & \multicolumn{8}{|c|}{ Kaolin, mixed in $5.8 \mathrm{M} \mathrm{HCl}$ for $6 \mathrm{~h}$ at room temperature } \\
\hline
\end{tabular}

*5.05 $\pm 0.02 \mathrm{~m} / \mathrm{m} \% 11 \mathrm{M} \mathrm{HCl}$-soluble and $0.50 \pm 0.02 \mathrm{~m} / \mathrm{m} \%$ structural iron, in $\mathrm{Fe}_{2} \mathrm{O}_{3}$ equivalents 


\section{Determination of the photochemical activity}

Thirty-five milligrams of surface-treated kaolinite was mixed into $35 \mathrm{~mL} 10^{-3} \mathrm{M}(\mathrm{COOH})_{2}$ solution. After mixing in a dark condition for $20 \mathrm{~min}$, the residual oxalic acid was determined by permanganometric titration $\left(5 * 10^{-3}\right.$ $\mathrm{M} \mathrm{KMnO}_{4}$ ). In this way, the surface-adsorbed oxalic acid was determined. Then, the sample was irradiated with a $\lambda_{\max }=365 \mathrm{~nm}$ UV light for $240 \mathrm{~min}$. Then, the residual oxalic acid was determined in the solution and the efficiency of the photochemical decomposition was determined.

\section{Structure elucidation methods}

\section{XRD, SSA and porosity}

X-ray powder diffraction (XRD) measurements were taken using a Philips PW 3710-type instrument $(\mathrm{CuK} \alpha$ radiation, $\lambda=1.54056 \AA, 50 \mathrm{kV}, 40 \mathrm{~mA}$ ), in the $4^{\circ}$ to $70^{\circ} 2 \theta$ range with a scanning speed of $0.02^{\circ} \mathrm{s}^{-1}$ and $1 \mathrm{~s} /$ step time. The finely powdered samples were loaded into back-packed mounts to eliminate preferential particle orientation.

The specific surface area, pore volume and pore size distribution in the micropore $(1.7-2 \mathrm{~nm})$, mesopore $(2-50 \mathrm{~nm})$ and the macropore (50-100 nm) diameter ranges were determined by nitrogen $\left(\mathrm{N}_{2}\right.$, Messer $\left.99.995 \%\right)$ adsorption/desorption isotherms. These were measured using a Micromeritics ASAP 2000-type instrument on samples ( 1 g mass) previously outgassed in vacuum at $60{ }^{\circ} \mathrm{C}$ temperatures. Pre-treatment of samples was considered to be completed when the vacuum pressure dropped below $10 \mu \mathrm{mHg}$. The surface areas of the samples were determined by the BET (Brunauer-Emmett-Teller) method from the corresponding nitrogen adsorption isotherms. The pore size distribution and pore volume values were calculated from the nitrogen desorption isotherms using the BJH (Barrett-Joyner-Halenda) model [19].

\section{${ }^{27}$ AI MAS NMR spectroscopy}

All NMR spectra were recorded on a Bruker Avance 9.4T spectrometer equipped with a 4-mm MAS BBO probe head. Spinning frequency was varied between 8 and $12 \mathrm{kHz}$ to differentiate peaks and spinning sidebands. Chemical shifts were referenced to an external standard. For all experiments, samples were packed under argon in a $\mathrm{Si}_{3} \mathrm{~N}_{4}$ rotor and closed with a Kel-F cap. In a typical ${ }^{27} \mathrm{Al}$ MAS experiment, 128 scans were acquired after a 90 degree pulse $(\nu R F=227 \mathrm{kHz})$ with $0.02-\mathrm{s}$ acquisition time and $83 \mathrm{kHz}$ spectral width allowing $50 \mathrm{~Hz}$ resolution. Additional relaxation delay was $5 \mathrm{~s} .{ }^{1} \mathrm{H}$ decoupling had no effect on the spectra; hence, it was switched off. The ${ }^{27} \mathrm{Al}$ MAS spectra showed a small background signal at $109 \mathrm{ppm}$. During the ${ }^{27} \mathrm{Al}$ CP MAS experiments, usually 512 scans were collected with the same window parameters and repetition rate as for the MAS experiment. The $\mathrm{CP}$ pulse strength for the ${ }^{27} \mathrm{Al}$ was optimized to reach Hartmann-Hahn condition.

\section{TG/DTG and CRTA measurements}

The TG/DTG and CRTA measurements were taken in a Derivatograph PC-type (MOM, Hungary) thermoanalytical equipment in a ceramic crucible under static air atmosphere at a heating rate of $5^{\circ} \mathrm{C} \mathrm{min}^{-1}$. The CRTA investigations were performed at a pre-set, constant rate of $0.05 \mathrm{mg} \mathrm{min}^{-1}$.

\section{TEM/STEM measurements}

Transmission electron microscope (TEM) investigations were carried out using a FEI Talos F200X-type electron microscope with a X-FEG electron source, operated at $200 \mathrm{kV}$ accelerator voltage. A SuperX EDX detector was used for the energy dispersive X-ray mode. The sample was prepared from an ultrasonicated aqueous dispersion (Milli$\mathrm{Q}$ water), onto a lacy carbon-coated copper grid, which was dried at $60{ }^{\circ} \mathrm{C}$ prior to measurement.

\section{Results and discussion}

\section{The effect of surface treatment on the mineral contaminants and on the porosity}

Based on the XRD pattern of Fig. 1, the untreated kaolin contains illite, orthoclase, quartz and albite mineral contaminants (PDF numbers: hematite (00-033-0664), goethite (01-081-0464), kaolinite (00-014-0164), orthoclase (00031-0966), albite (00-009-0466) and illite (00-026-0911)). The iron contamination is due to the presence of goethite and hematite. After treating with $5.8 \mathrm{M} \mathrm{HCl}$ for $6 \mathrm{~h}$, only goethite can be identified, which also disappears with the treatment with concentrated $\mathrm{HCl}$.

The effect of surface treatment on sample porosity is shown in Table 2. It can be stated that both the replacement intercalation/exfoliation (Knano, Knano-11 M HCl) and the acid treatment $(\mathrm{K}-5.8 \mathrm{M} \mathrm{HCl}, \mathrm{K}-11 \mathrm{M} \mathrm{HCl})$ result in the decrease of the SSA and the increase of the average pore diameter. It is interesting to see the behavior of samples Knano and Knano-11 M HCl. According to our experience, kaolins with iron-containing minerals show low exfoliation efficiency. Although now the thermal behavior of the samples is in focus, it is worth to pay attention to this interesting phenomenon. Based on the XRD data of the K-HA complex ('c' basal distance- $d_{001}$-about 18-28 $\AA$ ), it is supposed that hexylamine is present in the interlamellar gallery with a varying local geometry. Since the distance of the TO layers 

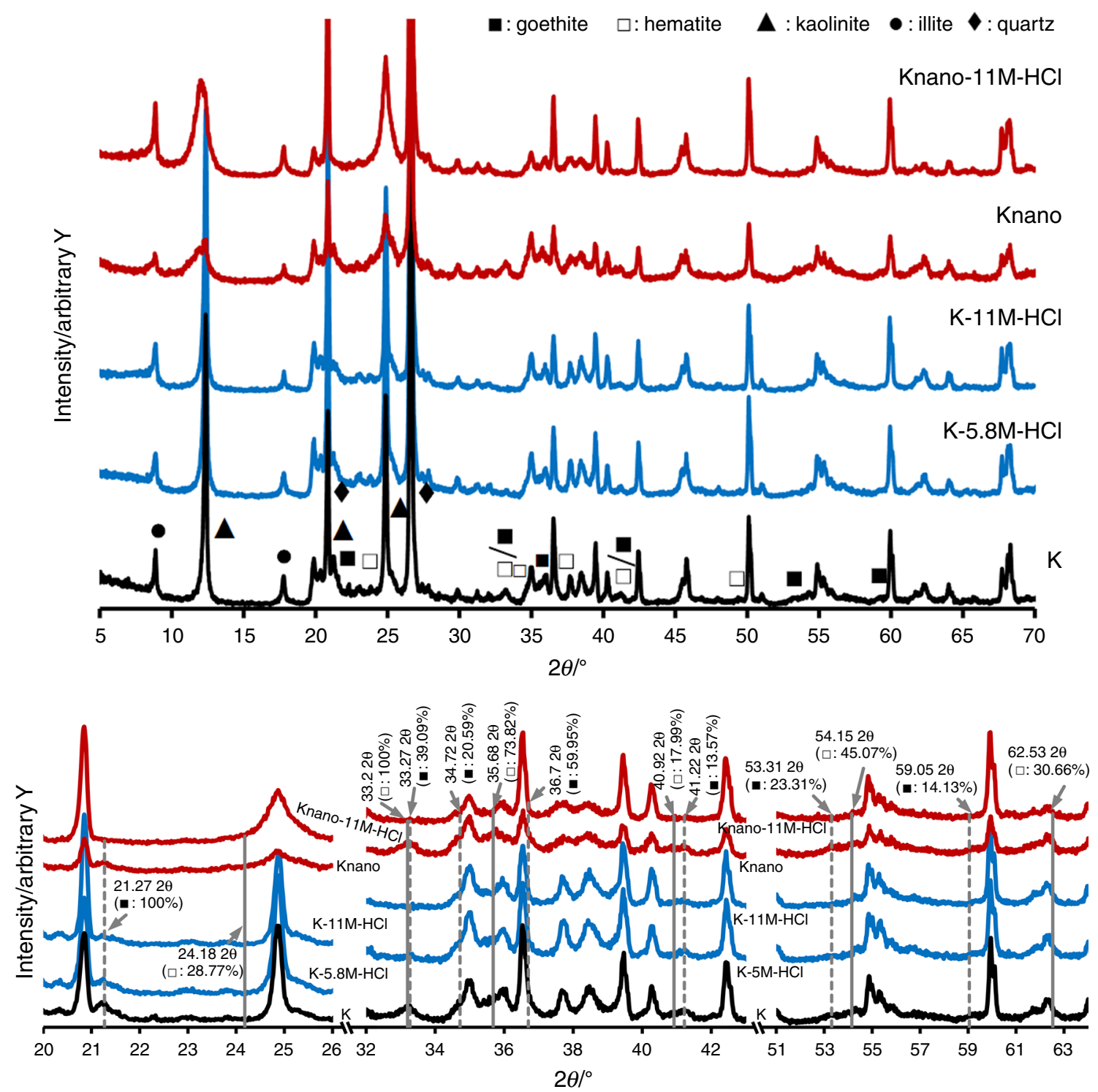

Fig. 1 The effect of acid treatment on the iron-containing mineral contaminants

Table 2 The effect of acid treatment on the SSA values. The efficiency of the photocatalytic decomposition of $(\mathrm{COOH})_{2}$ is also given

\begin{tabular}{lccccccc}
\hline Sample (treated at $60{ }^{\circ} \mathrm{C}$ ) & $\begin{array}{l}\mathrm{SSA}-F_{\mathrm{BET}} / \\
\mathrm{m}^{2} \mathrm{~g}^{-1}\end{array}$ & $\mathrm{SSA}-\mathrm{F}_{\mathrm{BJH}} / \mathrm{m}^{2} \mathrm{~g}^{-1}$ & $F_{\text {micro }} / \mathrm{cm}^{3} \mathrm{~g}^{-1}$ & $V_{\text {micro }} / \mathrm{cm}^{3} / \mathrm{g}$ & $V_{1,7-300} / \mathrm{cm}^{3} \mathrm{~g}^{-1}$ & $D_{\text {average }} / \mathrm{nm}$ & \\
\hline K & 16.9 & 15.5 & 2.1 & 0.0009 & 0.0556 & 11.6 \\
Knano & 16.5 & 18.0 & n.a & n.a. & 0.0608 & 12.2 \\
Knano-11 M HCl & 7.4 & 8.9 & n.a. & n.a. & 0.0619 & 24.6 \\
K-11 M HCl & 14.1 & 14.4 & 1.2 & 0.0004 & 0.0503 & 12 \\
K-5.8 M HCl & 14.1 & 15.3 & 0.8 & 0.0002 & 0.0567 & 14.0 \\
\hline
\end{tabular}

Type of pores: micro $x<2 \mathrm{~nm}$; meso $2<x \leq 50 \mathrm{~nm}$; macro $x>50 \mathrm{~nm}$

$\mathrm{SSA}-\mathrm{F}_{\mathrm{BET}} / \mathrm{m}^{2} \mathrm{~g}^{-1}$, specific surface area figures estimated by the Brunauer, Emmett and Teller (BET) method. SSA-F $\mathrm{BJH}_{\mathrm{H}} / \mathrm{m}^{2} \mathrm{~g}^{-1}$, estimated surface area values for cylindrical mesopores by the Barrett, Joyner and Halenda (BJH) theory. $\mathrm{V}_{1,7-300} / \mathrm{cm}^{3} \mathrm{~g}^{-1}$, the pore volume can be calculated for pores with 1.7 to $300 \mathrm{~nm}$ diameter with the Barrett, Joyner and Halenda (BJH) method. $\mathrm{D}_{\text {average }} / \mathrm{nm}$, average pore diameter. $\eta$, estimated photochemical decomposition efficiency of oxalic acid for surface-treated kaolin samples 
is big enough for the introduction of the iron-containing contaminant, the possible interaction between HA and the ironcontaining mineral can stabilize the K-HA complex. This idea is also supported by the fact that while the efficiency of the replacement intercalation is $\sim 95 \pm 3 \%$, the exfoliation efficiency (i.e., the separation of the layers into individual TO sheets) is $30 \pm 5 \%$, only. As a result, the Knano sample contains mixed phases (individual TO sheets and booktype layers). The calculation of the exfoliation efficiency from XRD data is more accurate when the re-ordering of the TO layers is negligible. If, however, with acidic treatment, washing (with toluene, methanol or water) or cleaning (with $\mathrm{H}_{2} \mathrm{O}_{2}$ ) of the surface the interaction between the nanosized particles (H bonds) increases, re-ordering can occur, resulting in the broadening/increased intensity of the $d(001)$ reflection. This can cause uncertainties in the determination of the exfoliation efficiency.

The porosity data of the Knano and the Knano- $11 \mathrm{M} \mathrm{HCl}$ samples can be interpreted as average values characteristic of the two phases. The acid treatment after exfoliation can increase the size and/or population of the mesopores, while the SSA value is drastically reduced, leading to the decrease of the catalytic efficiency.

However, from catalytic point of view, the increased pore size (caused by the surface treatment) is advantageous, since the diffusion is less controlled. It should be noted that the decrease of the SSA is not necessarily unfavorable, since the catalytic efficiency depends on several other factors, as well.

\section{Characterization of defect sites: ${ }^{27}$ AI MAS NMR spectroscopic investigations}

The change in $\mathrm{Al}$ coordination of the octahedral sheets was followed by ${ }^{27} \mathrm{Al}$ MAS NMR spectroscopy. In Fig. 2, the rotational bands identified at 10 and $8 \mathrm{kHz}$ are signed with “*” mark. Since the intensity of the coordinatively unsaturated sites is low, the determination of the band area ratios is uncertain. Thus, the spectra are useful for a qualitative comparison, only. The location and the symmetry of the bands are significantly influenced by the variety of the chemical environment. Based on literature values, the chemical shift data for the different $\mathrm{Al}$ coordinations are as follows: ${ }^{\mathrm{VI}} \mathrm{Al}$ : 4-7 ppm; ${ }^{\mathrm{V}} \mathrm{Al}$ : 20-35 ppm; ${ }^{\mathrm{IV}} \mathrm{Al}$ : 50-90 ppm [20-24]. In our samples, in addition to ${ }^{\mathrm{V}} \mathrm{Al},{ }^{\mathrm{IV}} \mathrm{Al}$ was identified, as well. Cross-polarization NMR spectra also showed that the tetrahedrally coordinated $\mathrm{Al}$ is mostly present inside of the sample.

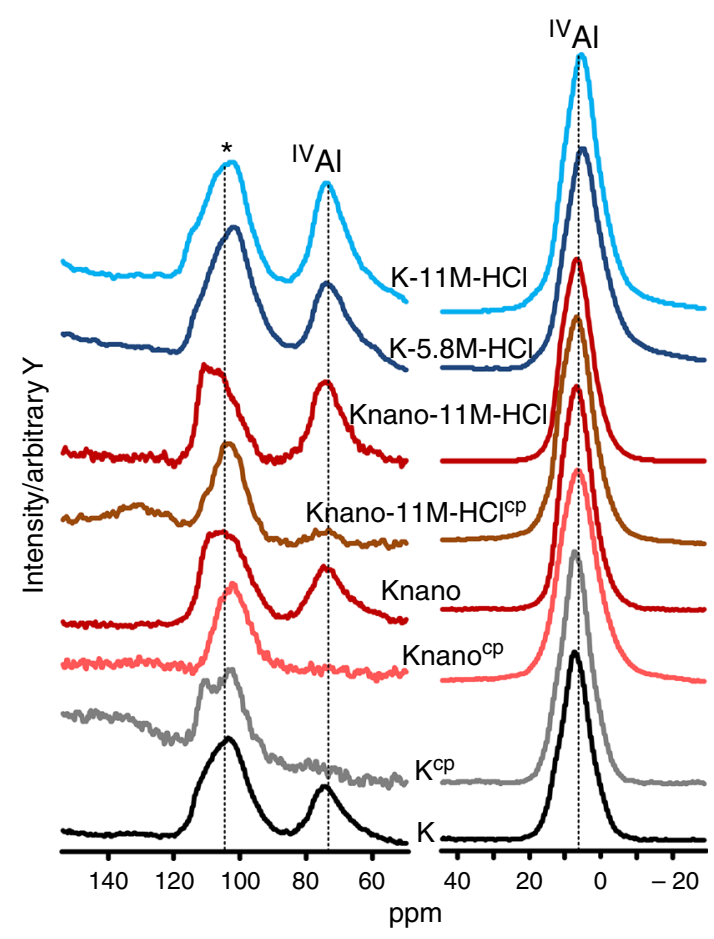

Fig. $2{ }^{27} \mathrm{Al}$ MAS NMR spectra of the surface-treated samples. The 'cp' annotation indicates cross-polarization spectra, while ' $*$ ' indicates the rotational bands

\section{Thermogravimetric (TG/DTG) and controlled-rate thermogravimetric (CRTA) analyses}

Thermoanalytical investigations were aimed at the discovery of the connection between surface treatment and the thermal behavior of the samples. This is important for two reasons: (1) On the one hand, the inner-surface $\mathrm{OH}$ and outer-surface $\mathrm{OH}$ groups can be protonated and their bonding strength can be changed in the vicinity of defect sites obtained via surface modification (or at already existing ones along edges or broken surfaces) [14]; (2) on the other hand, it is important to know what temperature ranges are suitable to produce composites/hybrids without changing the secondary structure and, in an ideal case, to form defect sites to increase catalytic activity.

The results of the thermoanalytical measurements are shown in Fig. 3. The mass loss and the corresponding temperature range data are summarized in Table 3 . 
Fig. 3 TG/DTG and CRTA curves of the pristine and surface-treated (intercalated/ exfoliated and acid-treated) kaolins in static air

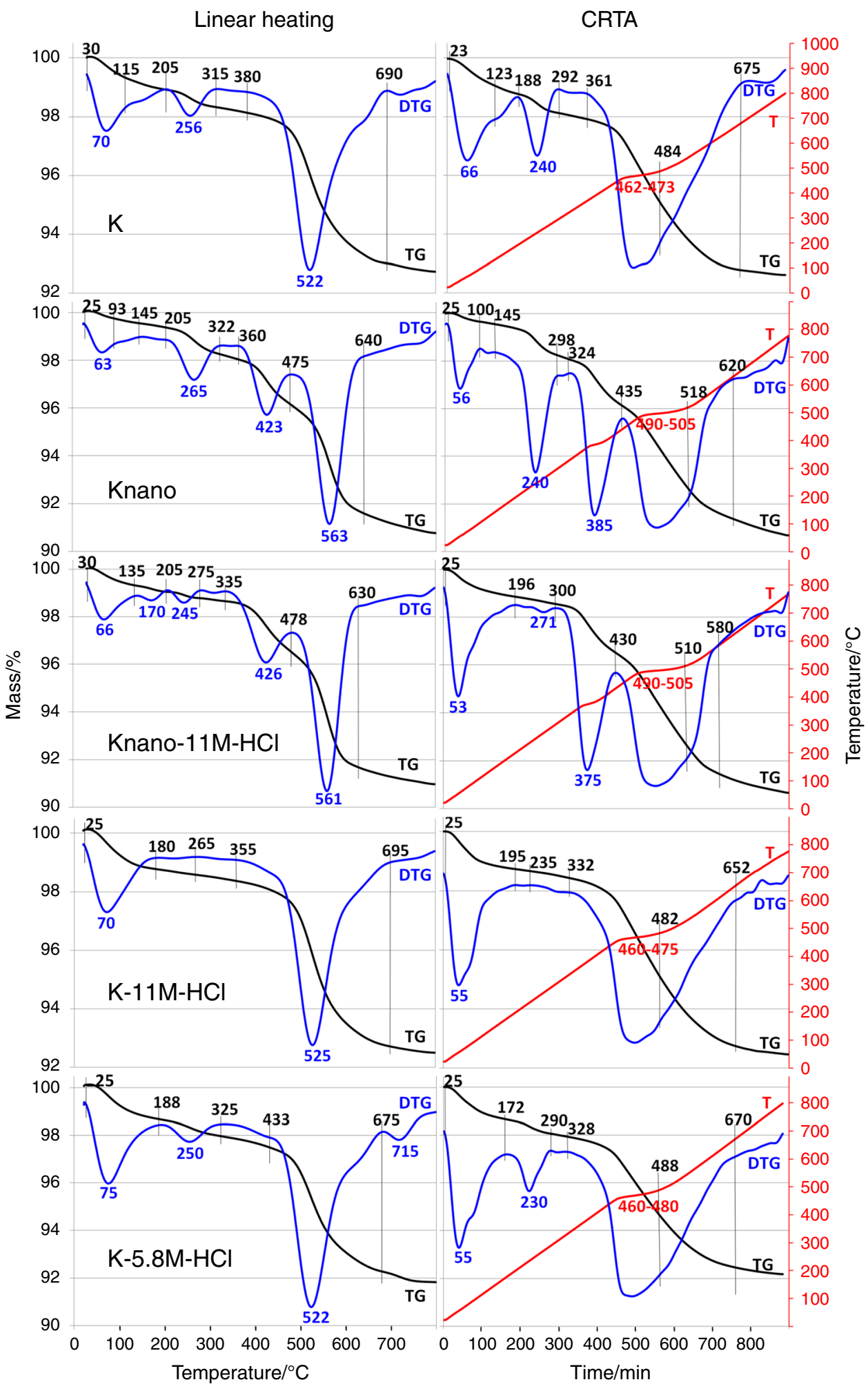

The DTG curves show three main decomposition ranges: (1) Up to about $200{ }^{\circ} \mathrm{C}$, adsorption water is lost; (2) between 200 and $350{ }^{\circ} \mathrm{C}$, the dehydroxylation of goethite and the liberation of coordinated water $\left(-\mathrm{OH}_{2}^{+}\right)$take place, along with the traces of residual organics (Knano,
Knano-11 M HCl); and (3) between 350 and $600{ }^{\circ} \mathrm{C}$, the strongly coordinated water is lost simultaneously with the dehydroxylation of the clay. 
Table 3 Temperature ranges and mass loss data

\begin{tabular}{|c|c|c|c|c|c|c|c|c|c|}
\hline & \multirow[t]{2}{*}{$\Delta T /{ }^{\circ} \mathrm{C}$} & \multirow[t]{2}{*}{$T_{\max } /{ }^{\circ} \mathrm{C}$} & \multicolumn{2}{|l|}{$\Delta m$} & & \multirow[t]{2}{*}{$\Delta T /^{\circ} \mathrm{C}$} & \multirow[t]{2}{*}{$T_{\max } /{ }^{\circ} \mathrm{C}$} & \multicolumn{2}{|l|}{$\Delta m$} \\
\hline & & & $/ \mathrm{mg}$ & $1 \%$ & & & & $/ \mathrm{mg}$ & $1 \%$ \\
\hline \multirow{7}{*}{$\begin{array}{l}\mathrm{K} \\
m=116.2 \mathrm{mg}\end{array}$} & $30-115$ & \multirow[t]{2}{*}{70} & 0.8 & 0.7 & \multirow{7}{*}{$\begin{array}{l}\text { CRTA } \\
m=231.0 \mathrm{mg}\end{array}$} & $23-123$ & \multirow[t]{2}{*}{66} & 2.0 & 0.9 \\
\hline & $115-205$ & & 0.5 & 0.4 & & $123-188$ & & 0.8 & 0.3 \\
\hline & $205-315$ & \multirow[t]{2}{*}{256} & 0.7 & 0.6 & & $188-292$ & \multirow[t]{2}{*}{240} & 1.5 & 0.6 \\
\hline & $315-380$ & & 0.2 & 0.2 & & $292-361$ & & 0.5 & 0.2 \\
\hline & $380-690$ & \multirow[t]{3}{*}{522} & 6.0 & 5.2 & & $361-484$ & \multirow[t]{3}{*}{$462-473$} & 6.3 & 2.7 \\
\hline & $690-760$ & & 0.3 & 0.3 & & $484-675$ & & 5.6 & 2.4 \\
\hline & & & & & & $675-800$ & & 0.4 & 0.2 \\
\hline \multirow{8}{*}{$\begin{array}{l}\text { Knano } \\
m=118.9 \mathrm{mg}\end{array}$} & $25-93$ & \multirow[t]{3}{*}{63} & 0.4 & 0.3 & \multirow{8}{*}{$\begin{array}{l}\text { CRTA } \\
m=228.8 \mathrm{mg}\end{array}$} & $25-100$ & \multirow[t]{2}{*}{56} & 0.8 & 0.3 \\
\hline & 93-145 & & 0.2 & 0.2 & & $100-145$ & & 0.3 & 0.1 \\
\hline & $145-205$ & & 0.2 & 0.2 & & $145-298$ & \multirow[t]{2}{*}{240} & 3.0 & 1.3 \\
\hline & $205-322$ & \multirow[t]{2}{*}{265} & 1.3 & 1.1 & & $298-324$ & & 0.3 & 0.1 \\
\hline & $322-360$ & & 0.2 & 0.2 & & $324-435$ & \multirow{4}{*}{$\begin{array}{l}385 \\
490-505\end{array}$} & 4.4 & 1.9 \\
\hline & $360-475$ & 423 & 2.2 & 1.9 & & $435-518$ & & 8.0 & 3.5 \\
\hline & $475-640$ & 563 & 5.5 & 4.6 & & $518-620$ & & 2.9 & 1.3 \\
\hline & $640-800$ & & 1.0 & 0.8 & & $620-771$ & & 1.7 & 0.7 \\
\hline \multirow{7}{*}{$\begin{array}{l}\text { Knano-11 M HCl } \\
m=110.5 \mathrm{mg}\end{array}$} & $30-135$ & 66 & 0.8 & 0.7 & \multirow{7}{*}{$\begin{array}{l}\text { CRTA } \\
m=220.5 \mathrm{mg}\end{array}$} & 25-196 & 53 & 2.5 & 1.1 \\
\hline & 135-205 & 170 & 0.3 & 0.3 & & 196-300 & 271 & 0.7 & 0.3 \\
\hline & $205-275$ & \multirow[t]{2}{*}{245} & 0.3 & 0.3 & & $300-430$ & & 4.5 & 2.0 \\
\hline & $275-335$ & & 0.2 & 0.2 & & $430-510$ & \multirow{4}{*}{$490-505$} & 8.2 & 3.7 \\
\hline & $335-478$ & 426 & 2.3 & 2.1 & & $510-580$ & & 2.8 & 1.3 \\
\hline & $478-630$ & \multirow[t]{2}{*}{561} & 5.4 & 4.9 & & $580-765$ & & 1.8 & 0.8 \\
\hline & $630-800$ & & 0.8 & 0.7 & & & & & \\
\hline $\mathrm{K}-11 \mathrm{M} \mathrm{HCl}$ & $25-180$ & 70 & 1.7 & 1.4 & CRTA & 25-195 & 55 & 2.9 & 1.2 \\
\hline$m=120.3 \mathrm{mg}$ & $180-265$ & & 0.2 & 0.2 & $m=232.5 \mathrm{mg}$ & $195-235$ & & 0.2 & 0.1 \\
\hline & $265-355$ & & 0.3 & 0.2 & & $235-332$ & & 0.5 & 0.2 \\
\hline & $355-695$ & 525 & 6.8 & 5.7 & & $332-482$ & $460-475$ & 7.6 & 3.3 \\
\hline & $695-800$ & & 0.3 & 0.2 & & $482-652$ & & 5.6 & 2.4 \\
\hline & & & & & & $652-770$ & & 0.7 & 0.7 \\
\hline $\mathrm{K}-5.8 \mathrm{M} \mathrm{HCl}$ & $25-188$ & 75 & 1.6 & 1.4 & CRTA & $25-172$ & 55 & 3.1 & 1.3 \\
\hline$m=111.3 \mathrm{mg}$ & $188-325$ & 250 & 0.8 & 0.7 & $m=234.1 \mathrm{mg}$ & $172-290$ & 230 & 1.4 & 0.6 \\
\hline & $325-433$ & & 0.5 & 0.4 & & $280-328$ & & 0.3 & 0.1 \\
\hline & $433-675$ & 522 & 5.8 & 5.2 & & $328-488$ & $460-480$ & 7.6 & 3.2 \\
\hline & $675-800$ & 715 & 0.5 & 0.4 & & $488-670$ & & 5.2 & 2.2 \\
\hline & & & & & & $670-795$ & & 0.7 & 0.3 \\
\hline
\end{tabular}

1. The removal of adsorbed water takes place in at least two strongly overlapping processes. This is due to the controlled diffusion and to the distribution of the adsorption energy determined by the chemical environment (energy distribution of the $\mathrm{H}$ bonds).

2. The mass loss between 250 and $350{ }^{\circ} \mathrm{C}$ is due to the dehydroxylation of goethite $(\mathrm{K}, \mathrm{Knano}, \mathrm{K}-5.8 \mathrm{M} \mathrm{HCl})$. In samples treated with $11 \mathrm{M} \mathrm{HCl}$, the loosely bonded coordination water (formed as a result of acid treatment) is lost up to $350{ }^{\circ} \mathrm{C}$. The origin of the decomposition products is also supported by the XRD data (see Chapter 3.1).

3. The dehydroxylation of the silicate backbone takes place in the $350-700{ }^{\circ} \mathrm{C}$ range. Dehydroxylation of the Knano and Knano-11 M HCl samples can be separated into two steps. The first step belongs to the exfoliated kaolinite phase (with DTG peak maxima at $423{ }^{\circ} \mathrm{C}$ and CRTA peak maxima at $385^{\circ} \mathrm{C}$ ), while the second belongs to the non-exfoliated mineral (with DTG peaks at $563{ }^{\circ} \mathrm{C}$ and CRTA peaks at $490-505^{\circ} \mathrm{C}$ ). It is important to note that the ratio of the exfoliated and the non-exfoliated phases ( $30 \%$ and $70 \%$, respectively) is in harmony with that obtained from the XRD data. Due to the higher accuracy of mass measurements, XRD data can be validated with the TG/DTG results (cif. Chapter 3.1). (The broadening of XRD peaks results in uncertainties in the determination of the phase ratios.) 
The overlap of the evolution of the strongly coordinated and dehydroxylation water is shown by the DTG and CRTA curves in the $\sim 350-450{ }^{\circ} \mathrm{C}$ range (especially for samples $\mathrm{K}-5.8 \mathrm{M} \mathrm{HCl}$ and $\mathrm{K}-11 \mathrm{M} \mathrm{HCl}$ ). Also (as shown by the CRTA curves), the dehydroxylation of the clay backbone shows two strongly overlapping steps (Fig. 3). A possible explanation can be the difference in bonding energy between the inner-surface $\mathrm{OH} /$ outer-surface $\mathrm{OH}$ groups in the regular octahedra and those ones in the vicinity of the $\mathrm{Fe}^{3+}$-substituted octahedra.

According to our experience, the liberation of the Zundel $\left(\mathrm{H}_{5} \mathrm{O}_{2}^{+}\right.$core $)$- and Eigen $\left(\mathrm{H}_{3} \mathrm{O}^{+}\right.$core $)$-type water strongly overlaps with that of the coordinated water. Also, dehydroxylation of the silicate backbone begins above $350{ }^{\circ} \mathrm{C}$. The decomposition step between 300 and $400{ }^{\circ} \mathrm{C}$ is of importance because the evolving water can significantly influence the applicability of the TPD (temperate-programmed desorption) method aimed at the determination of the acid-base character of the surface [25-28]. To reduce measurement uncertainty, it is necessary to preliminary determine the pretreatment temperatures of the samples with thermal analysis.
On the other hand, the preparation of some of the mixedoxide composites/hybrids takes place in the $250-400{ }^{\circ} \mathrm{C}$ range that partly overlaps with the dehydroxylation of the silicate backbone, resulting in the formation of coordinately unsaturated (defect) sites. Other oxides (e.g., $\mathrm{ZnO}$ ) are formed in the upper temperature range of dehydroxylation $\left(550-700{ }^{\circ} \mathrm{C}\right)$, where-depending on the amount of the remaining $\mathrm{OH}$ groups - a residual photochemical activity of $20-30 \%$ is experienced (unpublished result).

Table 4 contains the temperature ranges in which defect sites can be formed during the preparation of oxide composites. (With TPD experiments, systematic error can also occur due to the simultaneous liberation of the test material and water.) The temperature ranges of the individual steps are determined based on Fig. 1. The data of Table 4 show thatdue to the strongly overlapping thermal events- the total amounts of water can significantly deviate from the average figures, independently of the fact that linear or CRTA heating was used. The overlapping thermal events have morphological reasons, mainly the presence of micropores (e.g., in sample K), the simultaneous presence of the book-type and
Table 4 Mass loss $\left(\mathrm{H}_{2} \mathrm{O}\right.$, $\mathrm{mmol} / 100 \mathrm{~g}$ sample) and $\mathrm{OH}$ group $(\mathrm{OH}, \mathrm{mmol} / 100 \mathrm{~g}$ sample) values corresponding to the temperature ranges of composite/hybrid preparation

\begin{tabular}{|c|c|c|c|c|c|c|}
\hline & \multicolumn{3}{|c|}{ Linear heating } & \multicolumn{3}{|c|}{ CRTA heating } \\
\hline & $\Delta T /{ }^{\circ} \mathrm{C}$ & $\begin{array}{l}\mathrm{H}_{2} \mathrm{O} \\
/ \mathrm{mmol}\end{array}$ & $\begin{array}{l}\mathrm{OH} \\
/ \mathrm{mmol} /(\%)\end{array}$ & $\Delta T /{ }^{\circ} \mathrm{C}$ & $\begin{array}{l}\mathrm{H}_{2} \mathrm{O} \\
/ \mathrm{mmol}\end{array}$ & $\begin{array}{l}\mathrm{OH} \\
/ \mathrm{mmol} / \\
(\%)\end{array}$ \\
\hline \multirow[t]{5}{*}{ K } & $\Sigma / \mathrm{mmol}$ & 0.317 & 0.633 & $\Sigma / \mathrm{mmol}$ & 0.306 & 0.611 \\
\hline & $315-380$ & 0.011 & (3.5) & $292-361$ & 0.011 & (3.6) \\
\hline & $380-690$ & 0.289 & (91.3) & $361-484$ & 0.150 & $(49.1)$ \\
\hline & $690-760$ & 0.016 & $(5.2)$ & $484-675$ & 0.133 & $(43.7)$ \\
\hline & - & - & - & $675-800$ & 0.011 & (3.6) \\
\hline \multirow[t]{6}{*}{ Knano } & $\Sigma / \mathrm{mmol}$ & 0.372 & 0.833 & $\Sigma / \mathrm{mmol}$ & 0.417 & 0.833 \\
\hline & $322-360$ & 0.011 & (2.6) & $298-324$ & 0.050 & (1.3) \\
\hline & $360-475$ & 0.105 & $(25.3)$ & $324-435$ & 0.105 & $(25.3)$ \\
\hline & $475-640$ & 0.255 & $(61.3)$ & $435-518$ & 0.195 & $(46.7)$ \\
\hline & $640-800$ & 0.044 & $(10.8)$ & $518-620$ & 0.072 & $(17.3)$ \\
\hline & - & - & - & $620-771$ & 0.039 & (9.4) \\
\hline \multirow[t]{5}{*}{ Knano-11 M HCl } & $\Sigma / \mathrm{mmol}$ & 0.428 & 0.855 & $\Sigma / \mathrm{mmol}$ & 0.433 & 0.866 \\
\hline & $335-478$ & 0.116 & $(27.3)$ & $300-430$ & 0.111 & $(25.6)$ \\
\hline & $478-630$ & 0.272 & $(63.6)$ & $430-510$ & 0.205 & $(47.5)$ \\
\hline & $630-800$ & 0.039 & $(9.1)$ & $510-580$ & 0.072 & $(16.6)$ \\
\hline & - & - & - & $580-765$ & 0.044 & $(10.3)$ \\
\hline \multirow[t]{4}{*}{$\mathrm{K}-11 \mathrm{M} \mathrm{HCl}$} & $\Sigma / \mathrm{mmol}$ & 0.328 & 0.655 & $\Sigma / \mathrm{mmol}$ & 0.356 & 0.712 \\
\hline & $355-695$ & 0.316 & $(96.6)$ & $332-482$ & 0.183 & $(51.5)$ \\
\hline & $695-800$ & 0.011 & (3.4) & $482-652$ & 0.133 & $(37.5)$ \\
\hline & - & - & - & $652-770$ & 0.039 & (11.0) \\
\hline \multirow[t]{5}{*}{$\mathrm{K}-5.8 \mathrm{M} \mathrm{HCl}$} & $\Sigma / \mathrm{mmol}$ & 0.333 & 0.666 & $\Sigma / \mathrm{mmol}$ & 0.321 & 0.643 \\
\hline & $325-433$ & 0.022 & $(6.6)$ & $290-328$ & 0.005 & (1.7) \\
\hline & $433-675$ & 0.289 & $(86.8)$ & $328-488$ & 0.177 & $(55.3)$ \\
\hline & $675-800$ & 0.022 & (6.6) & $488-670$ & 0.122 & (37.9) \\
\hline & - & - & - & $670-795$ & 0.016 & $(5.1)$ \\
\hline
\end{tabular}

The total average amount of water lost in the dehydroxylation step is $0.356 \mathrm{mmol} / 100 \mathrm{~g}$ with linear and $0.367 \mathrm{mmol} / 100 \mathrm{~g}$ with CRTA heating, respectively 
exfoliated phase (Knano) and the diversity in the activation energy of the protonated $\mathrm{OH}$ groups.

\section{TEM investigations with element mapping (EDX)}

The TEM photographs of the pristine and surface-modified samples $(\mathrm{K}, \mathrm{K}-5.8 \mathrm{M} \mathrm{HCl}, \mathrm{K}-11 \mathrm{M} \mathrm{HCl})$ are shown in Figs. 4 and 5, respectively, along with the Ti and Fe maps.

In accordance with the XRD results, the untreated mineral has well-crystallized goethite, hematite and (in a lower amount) $\mathrm{TiO}_{2}$ phases (Fig. $4 \mathrm{~A} / 1$ and $\mathrm{A} / 2-\mathrm{EDX}(\mathrm{Ti}, \mathrm{Fe}$ )).

After the treatment with $5.8 \mathrm{M} \mathrm{HCl}$, some goethite is still present on the surface of the clay particles. The acid treatment shows no influence on the $\mathrm{TiO}_{2}$ phase (Fig. 5 B-EDX $(\mathrm{Fe}, \mathrm{Ti})$ ). After the treatment with $11 \mathrm{M} \mathrm{HCl}$, amorphous, spot-like Fe structures remain on the surface, which can be explained with precipitation of iron chloride from the acidic solution. With EDX, $\mathrm{Cl}$ was present at the detection level. In addition, it is reasonable to suppose the presence of $\mathrm{Fe}(\mathrm{OH})_{2}$ and/or $\mathrm{Fe}(\mathrm{OH})_{3}$, as well. In addition, ICP analysis showed the prolonged treatment with $11 \mathrm{M} \mathrm{HCl}$ dissolved in $0.11 \pm 0.01 \mathrm{~m} / \mathrm{m} \% \mathrm{Al}$ from the structure (which could be replaced by iron).

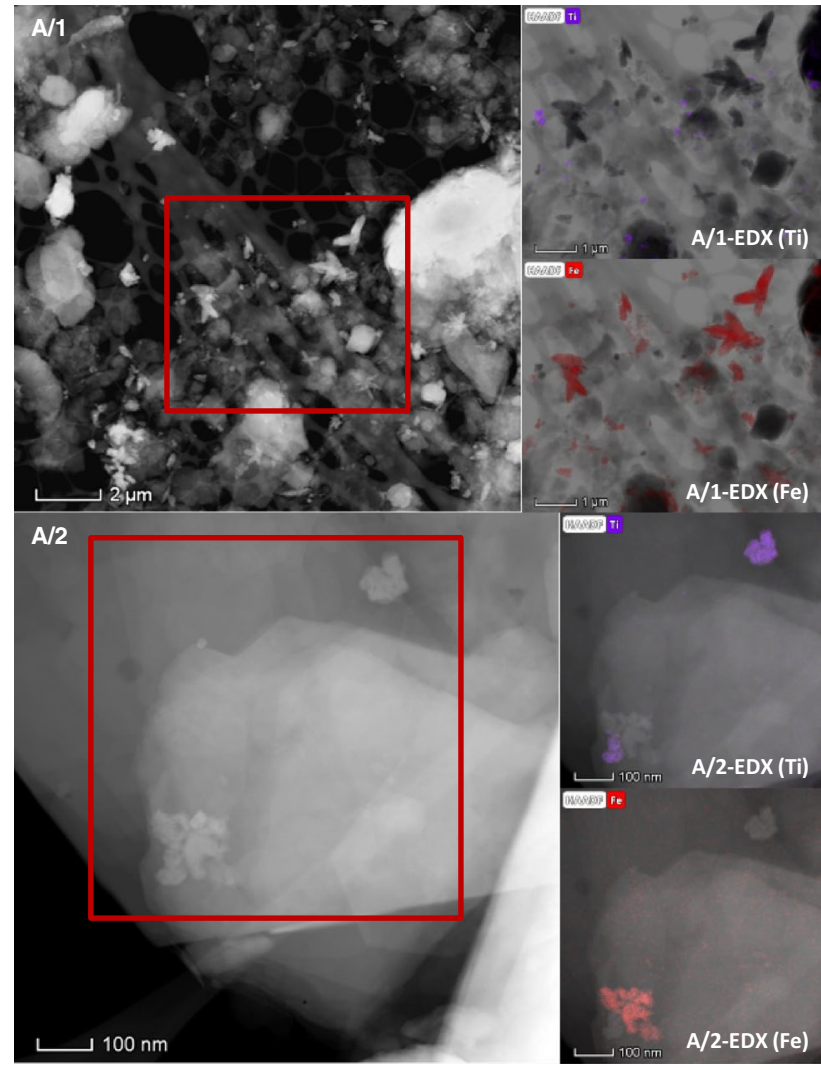

Fig. 4 STEM images of $K$ sample (A/1, A/2) and EDX mappings for $\mathrm{Ti}$ and $\mathrm{Fe}$ elements from designated areas

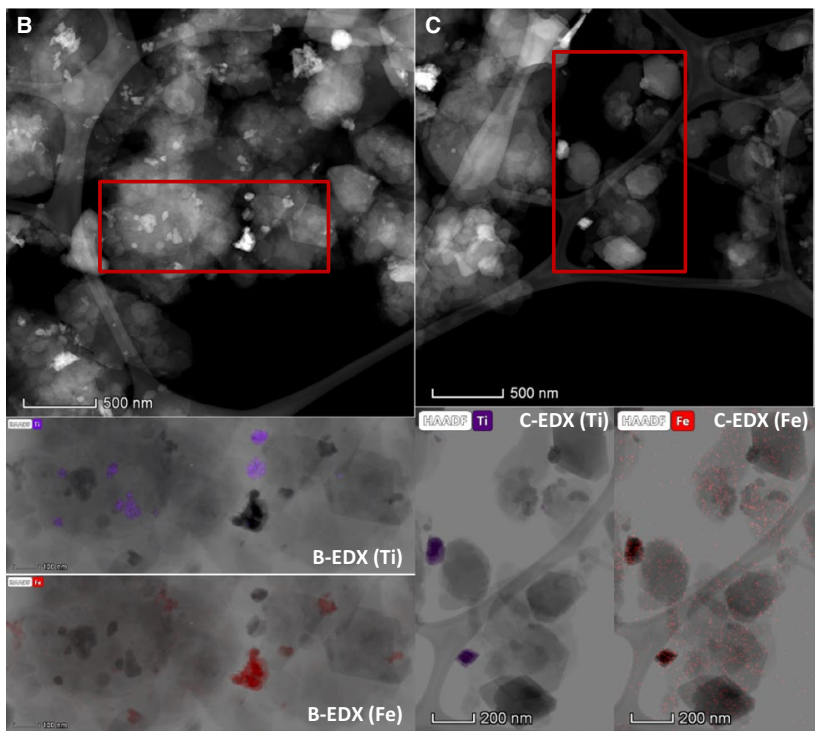

Fig. 5 STEM images of $\mathrm{K}-5.8 \mathrm{M} \mathrm{HCl}(\mathbf{b})$ and $\mathrm{K}-11 \mathrm{M} \mathrm{HCl}$ (c) samples and EDX mappings for $\mathrm{Ti}$ and Fe elements from designated areas

\section{Conclusions}

The development of clay-based catalysts requires the preparation of defect sites in the clay structure. From practical reasons, acid treatment is preferred, especially when ironcontaining mineral contaminants are present.

The high iron content of the samples makes thermal analysis significantly more difficult. The iron contamination of clay minerals is usually caused by oxides, hydroxides and carbonates present as accompanying phases. In the kaolin samples studied, hematite $\left(\mathrm{Fe}_{2} \mathrm{O}_{3}\right)$ and goethite $(\alpha-\mathrm{FeOOH})$ are present. Depending on the degree of crystallinity, dehydroxylation of goethite takes place in the $250-350{ }^{\circ} \mathrm{C}$ range [29]. Depending on the strength of acidic treatment and on the origin of kaolin, acid treatment can partially destruct the silicate backbone. It is proved, however, that $\mathrm{HCl}$ has no destructive effect [30]. On the other hand, the $\mathrm{OH}$ groups can be protonated at the surfaces and at the edges after acidic treatment and a cation exchange can occur (replacement of $\mathrm{Al}$ by $\mathrm{Fe}$ in the octahedra). The binding energy of the protonated $\mathrm{OH}$ groups is comparable with that of coordinated water molecules and-depending on their chemical environment-fall into the $50-200 \mathrm{kJmol}^{-1}$ range as determined by atomic-scale structural and energetic simulations. Thus, their dehydroxylation requires higher energy than for the removal of adsorbed water, but a lower one which is necessary for the removal of the structural $\mathrm{OH}$ groups [14]. This is of importance from several points of view. The dehydroxylation of goethite, the removal of the $-\mathrm{OH}_{2}{ }^{+}$groups and the dehydroxylation of the kaolinite show strongly overlapping 
processes, leading to uncertain mass loss values. (In each step, only water is lost.) On the other hand, this could be disturbing (e.g., with the use of the TPD method), since the $-\mathrm{OH}_{2}{ }^{+}$groups can have a blocking effect at the coordinatively unsaturated sites or the agent used for surface titration is liberated along with the loss of water. In both cases, uncertain measurement results can be obtained.

Thermal analysis can advantageously be used for modeling the conditions of preparation of kaolinite-based oxide catalysts and hybrid composites, since the extent of defect site formation via the destruction/dehydroxylation of the structure can be estimated from the mass loss data.

Acknowledgements Open access funding provided by University of Pannonia (PE). Access to powder X-ray diffraction, NMR spectroscopic and TEM (Nanolab) microscopic instrumentation at University of Pannonia is acknowledged. The financial support of the GINOP2.3.2-15-2016-00016 and GINOP-2.3.2-15-2016-00053 projects (cofinanced by the Széchenyi 2020 program) is also acknowledged.

Open Access This article is licensed under a Creative Commons Attribution 4.0 International License, which permits use, sharing, adaptation, distribution and reproduction in any medium or format, as long as you give appropriate credit to the original author(s) and the source, provide a link to the Creative Commons licence, and indicate if changes were made. The images or other third party material in this article are included in the article's Creative Commons licence, unless indicated otherwise in a credit line to the material. If material is not included in the article's Creative Commons licence and your intended use is not permitted by statutory regulation or exceeds the permitted use, you will need to obtain permission directly from the copyright holder. To view a copy of this licence, visit http://creativecommons.org/licenses/by/4.0/.

\section{References}

1. Long M, Zhang Y, Shu Z, Tang A, Ouyang J, Yang $\mathrm{H} . \mathrm{Fe}_{2} \mathrm{O}_{3}$ nanoparticles anchored on 2D kaolinite with enhanced antibacterial activity. Chem Commun. 2017;53:6255-8. https://doi. org/10.1039/c7cc02905e.

2. Mamulová Kutláková K, Tokarský J, Peikertová P. Functional and eco-friendly nanocomposite kaolinite/ZnO with high photocatalytic activity. Appl Catal B Environ. 2015;162:392-400. https:// doi.org/10.1016/j.apcatb.2014.07.018.

3. Shao GN, Engole M, Imran SM, Jeon SJ, Kim HT. Sol-gel synthesis of photoactive kaolinite-titania: effect of the preparation method and their photocatalytic properties. Appl Surf Sci. 2015;331:98-107. https://doi.org/10.1016/j.apsusc.2014.12.199.

4. Kibanova D, Trejo M, Destalliats H, Cervinisilva J. Synthesis of hectorite- $\mathrm{TiO}_{2}$ and kaolinite- $\mathrm{TiO}_{2}$ nanocomposites with photocatalytic activity for the degradation of model air pollutants. Appl Clay Sci. 2009;42:563-8. https://doi.org/10.1016/j. clay.2008.03.009.

5. Hu KH, Liu Z, Huang F, Hu XG, Han CL. Synthesis and photocatalytic properties of nano-MoS2/kaolin composite. Chem Eng J. 2010;162:836-43. https://doi.org/10.1016/j.cej.2010.06.011.

6. Koutsopoulou E, Papoulis D, Tsolis-Katagas P, Kornaros M. Clay minerals used in sanitary landfills for the retention of organic and inorganic pollutants. Appl Clay Sci. 2010;49:372-82. https://doi. org/10.1016/j.clay.2010.05.004.
7. Shirzad-Siboni M, Farrokhi M, Darvishi Cheshmeh Soltani R, Khataee A, Tajassosi S. Photocatalytic reduction of hexavalent chromium over $\mathrm{ZnO}$ nanorods immobilized on Kaolin. Ind Eng Chem Res. 2014;53:1079-87. https://doi.org/10.1021/ie4032583.

8. Sia TH, Dai S, Jin B, Biggs M, Chong MN. Hybridising nitrogen doped titania with kaolinite: a feasible catalyst for a semicontinuous photo-degradation reactor system. Chem Eng J. 2015;279:939-47. https://doi.org/10.1016/j.cej.2015.05.101.

9. Stucki JW, Goodman BA, Schwertmann U. Iron in soils and clay minerals. Dordrecht: D. Reidel Publishing Company; 1985.

10. Rengasamy P. Isomorphous substitution of iron for aluminium in some soil kaolinites. Clays Clay Miner. 1975;23:211-4. https:// doi.org/10.1346/CCMN.1975.0230308.

11. West MW. Chemical evolution and the origin of life. Orig Life. 1977;8:283. https://doi.org/10.1007/BF00930691.

12. Sheikholeslami Z, Yousefi Kebria D, Qaderi F. Investigation of photocatalytic degradation of BTEX in produced water using $\gamma$ - $\mathrm{Fe}_{2} \mathrm{O}_{3}$ nanoparticle. J Therm Anal Calorim. 2019;135:1617-27. https://doi.org/10.1007/s10973-018-7381-x.

13. Kirichenko O, Strekalova A, Kapustin G, Shesterkina A, Redina E, Kustov L. Redox behavior of novel $\mathrm{FeO} x / \mathrm{Pd} / \mathrm{SiO}_{2}$ catalytic nanomaterials. J Therm Anal Calorim. 2019;138:1913-22. https ://doi.org/10.1007/s10973-019-08786-5.

14. Zsirka B, Táborosi A, Szabó P, Szilágyi RK, Horváth E, Juzsakova T. Surface characterization of mechanochemically modified exfoliated halloysite nanoscrolls. Langmuir. 2017;33:3534-47. https ://doi.org/10.1021/acs.langmuir.6b04606.

15. Milićević S, Martinović S, Milošević V, Stojanović J, Povrenović D. Differences in coating mechanism of structurally different aluminosilicates observed through the thermal analysis. J Therm Anal Calorim. 2018;134:1011-9. https://doi.org/10.1007/s1097 3-018-7351-3.

16. Farhana K, Kadirgama K, Rahman MM, Noor MM, Ramasamy D, Samykano M. Significance of alumina in nanofluid technology. J Therm Anal Calorim. 2019;138:1107-26. https://doi.org/10.1007/ s10973-019-08305-6.

17. Erdogan Alver B. Thermal and gas $\left(\mathrm{CH}_{4}\right.$ and $\left.\mathrm{C}_{2} \mathrm{H}_{4}\right)$ adsorption characteristics of nitric acid-treated clinoptilolite. J Therm Anal Calorim. 2019;135:2917-24. https://doi.org/10.1007/s1097 3-018-7503-5.

18. Zsirka B, Horváth E, Makó É, Kurdi R, Kristóf J. Preparation and characterization of kaolinite nanostructures: reaction pathways, morphology and structural order. Clay Miner. 2015;50:329-40. https://doi.org/10.1180/claymin.2015.050.3.06.

19. Sing KSW, Everett DH, Haul RAW, Moscou L, Pierotti RA, Rouquerol J. Reporting physisorption data for gas/solid systems. Weinheim: Wiley; 2008.

20. Schroeder PA, Pruett RJ. Fe ordering in kaolinite; insights from 29 Si and 27 Al MAS NMR spectroscopy. Am Miner. 1996;81:2638. https://doi.org/10.2138/am-1996-1-204.

21. Doubi HG, Montouillout V, Lecomte Nana GL, Nait Ali B, Konan LK, Smith A. 29Si and 27Al MAS NMR characterization of the structural evolution of a lateritic clay under acidic and alkaline treatments. J Mater Sci Eng. 2018;07:1-7. https://doi. org/10.4172/2169-0022.1000409.

22. Barrow NS, Scullard A, Collis N. Surface selective $1 \mathrm{H}$ and 27 Al MAS NMR observations of strontium oxide doped $\gamma$-alumina surface binding sites of strontium oxide on $\gamma$-alumina identified for the first time. Johnson Matthey Technol Rev. 2016;60:90-7. https://doi.org/10.1595/205651316x690943.

23. van Bokhoven JA, Koningsberger DC, Kunkeler P, van Bekkum $\mathrm{H}$, Kentgens APM. Stepwise dealumination of zeolite $\beta$ eta at specific T-sites observed with 27 Al MAS and 27 Al MQ MAS NMR. J Am Chem Soc. 2000;122:12842-7. https://doi.org/10.1021/ ja002689d. 
24. Sreeja V, Smitha TS, Nand D, Ajithkumar TG, Joy PA. Size dependent coordination behavior and cation distribution in $\mathrm{MgAl}_{2} \mathrm{O}_{4}$ nanoparticles from $27 \mathrm{Al}$ solid state NMR studies. J Phys Chem C. 2008;112:14737-44. https://doi.org/10.1021/jp800 $412 \mathrm{k}$.

25. Novikova L, Roessner F, Belchinskaya L, AlSawalha M, Krupskaya V. Study of surface acid-base properties of natural clays and zeolites by the conversion of 2-methylbut-3-yn-2-ol. Appl Clay Sci. 2014;101:229-36. https://doi.org/10.1016/j.clay.2014.08.005.

26. Solyman SM, Betiha MA. The performance of chemically and physically modified local kaolinite in methanol dehydration to dimethyl ether. Egypt J Pet. 2014;23:247-54. https://doi. org/10.1016/j.ejpe.2014.08.001.

27. Alsawalha M. Properties and characterizations of different natural Jordanian materials. Am J Mater Sci. 2016;6:87-90. https://doi. org/10.5923/j.materials.20160604.01.
28. Kumar S, Panda AK, Singh RK. Preparation and characterization of acid and alkaline treated kaolin clay. Bull Chem React Eng Catal. 2013;8:61-9. https://doi.org/10.9767/bcrec.8.1.4530.61-69.

29. Földvári M. A Földtani kutatásban alkalmazott termoanalitikai módszerek. In: Tóthné Makk Á, editor, Módszertani közlemények IX. 1986/1. Budapest: Magyar Állami Földtani Intézet; 1986. p. $15-54$.

30. Stepova K, Maquarrie D, Krip I. Modified bentonites as adsorbents of hydrogen sulfide gases. Appl Clay Sci. 2009;42:625-8. https://doi.org/10.1016/j.clay.2008.05.001.

Publisher's Note Springer Nature remains neutral with regard to jurisdictional claims in published maps and institutional affiliations. 